\title{
Inhibitory Control, Student-Teacher Relationships, and Expulsion Risk in Preschools: An Indirect Effects Path Analysis
}

\author{
Alysse M. Loomis ${ }^{1}$ (D) Sasha Freed ${ }^{1} \cdot$ Rachel Coffey $^{1}$
}

Accepted: 18 November 2021 / Published online: 7 January 2022

(c) The Author(s), under exclusive licence to Springer Nature B.V. 2021

\begin{abstract}
Identifying factors related to expulsion risk is of great need due to the high and disparate rates of young children routinely excluded from preschool classrooms. This study aimed to explore the pathways to expulsion risk among a sample of 88 preschool children from 22 Head Start classrooms. Data were collected on children's inhibitory control using the Child Behavior Questionnaire, the closeness subscale of the Student-Teacher Relationship Scale, and on children's overall expulsion risk using the Preschool Expulsion Risk Measure. Direct pathways from children's inhibitory control and student-teacher closeness to expulsion risk were significant. Results indicated that student-teacher closeness mediated the relationship between children's inhibitory control and expulsion risk, indicating the importance of supporting positive relationships in preschool classrooms to disrupt pathways to expulsion. Implications for practices and future research to prevent expulsion are discussed.
\end{abstract}

Keywords Child behavior · Discipline $\cdot$ Early care and education

\section{Introduction}

\section{Preschool Expulsion}

Despite growing evidence of the high and disparate rates of preschool expulsion since the early 2000's, young children continue to get expelled and excluded from early care and education settings, impacting school readiness and long-term educational trajectories for thousands of children annually. In the first study of preschool expulsion in 2005, Walter Gilliam used data from the National Prekindergarten Study from 40 states that fund pre-k and showed that in all states but three, the rates of expulsion for preschoolers was higher than those for children in grades K-12 (Gilliam, 2005). Notably, preschoolers were expelled on average 3.2 times more than older children, boys were 4.5 times more likely than girls to face expulsion, and Black children were twice as likely to be expelled as Latine or White children (Gilliam, 2005). More recent information from the National Survey of Children's Health found that this continues to be a big issue, every day there are about 250 instances of a

Alysse M. Loomis

alysse.loomis@utah.edu

1 College of Social Work, University of Utah, 395 South 1500 East \#111, Salt Lake City, UT 84112, USA child being suspended or expelled from preschool, adding up to about 50,000 children suspended and 17,000 children expelled at least once from preschool in 2016 (Malik, 2017). This issue is not restricted to center-based preschool settings; in a recent study $13.3 \%$ of home-based child care centers reported expelling a child in the last year (Hooper $\&$ Schweiker, 2020).

Young children of color, and particularly Black children, are higher risk of being excluded from school settings. For example, while Black children make up about $18 \%$ of preschoolers nationally, they make up $42 \%$ of children who are suspended from preschool (U.S. Department of Education Office for Civil Rights, 2014). Similarly, in a 2020 study of suspension and expulsion in community-based child care centers, Black students made up $8.6 \%$ of the population but $24 \%$ of children expelled (Giordano et al., 2020). In fact, Black children are more likely to be excluded from school in every single state (Children's Equity Project \& the Bipartisan Policy Center, 2020). More recent work has also found that Latine, ${ }^{1}$ and American Indian preschoolers and older students all have documented higher rates of expulsion

\footnotetext{
${ }^{1}$ We use Latine throughout the paper to refer to individuals with cultural backgrounds originating in Latin America. Latine, with the Spanish language gender-inclusive ending, is being increasingly used by experts in the field as an alternate to Latinx (Iruka et al., 2021; Melzi et al., 2020).
} 
compared to White students (Giordano et al., 2020; SNAHEC, 2019; Zeng et al., 2019).

The high and disparate rates of suspension and expulsion are especially concerning given that we know that overall, suspension and expulsion doesn't improve children's outcomes. Mounting evidence suggests that suspension and expulsion from school actually places children on a trajectory to do worse in school, have worse relationships with their teachers, get punished more frequently, and be at higher risk of dropping out (Noltemeyer et al., 2015). In addition, children who are suspended and expelled from school are actually more likely to end up incarcerated-a snowball of consequences and experiences linked to school exclusion that has been called the school to prison pipeline, or in this case the preschool to prison pipeline (Hughes et al., 2020). In fact, a recent study suggested that racial inequalities in arrest rates would decrease by as much as $16 \%$ if we were able to equalize the risk of school-based punishment between Black and White school children (Barnes \& Motz, 2018), demonstrating the need to identify predictors of expulsion that can be targeted to reduce overall and disparate rates of early exclusionary discipline.

\section{Predictors of Expulsion}

Just as with older children, challenging behaviors in the classroom are one of the most prevalent causes for expulsion cited by teachers. In interviews with teachers who had expelled a preschooler, teachers share that they first often look for causes and solutions to challenging behaviors for students, but when these solutions fail, their perception of student behaviors shift from "struggling child" to "unsafe child and bad parents" - a shift that is linked to a higher likelihood of expelling a child (Martin et al., 2018). Further, children who experience higher rates of adverse childhood experiences, such as witnessing violence, are more likely to be suspended or expelled (Zeng et al., 2019), which may make sense given the link between exposure to trauma and adversity and behavioral struggles.

One behavioral indicator that may increase a child's risk of expulsion is their inhibitory control, or ability to suppress inappropriate responses when instructed or in new and stimulating circumstances. For example, being able to stop an activity when a teacher asks a child to or when it is time for a transition in the classroom. A child with poor inhibitory control skills may be seen as defiant or difficult to manage. Inhibitory control is related to externalizing behaviors later in childhood as well (Kahle et al., 2018). Inhibitory control has also been linked to children's experiences of early adversity (Skowron et al., 2014), and may be one mechanism through which adversity influences expulsion risk.

While problematic behaviors, such as poor inhibitory control, in a classroom can be challenging for teachers, other factors can also affect a child's risk of expulsion on the teacher level. For example, factors such as a teacher's perceptions of parents (Martin et al., 2018), teacher stress levels (Zinsser et al., 2017), lack of center support (Zulauf \& Zinsser, 2019), teacher perception of availability of behavioral supports (Miller et al., 2017), and classroom size (Gilliam \& Shahar, 2006) have all been associated with preschool children's expulsion risk. Of note, many of these predictors are tied to that lens through which teachers perceive a child's behavior, whether it's how they're interpreting the child's behavior or things in the environment that may increase a teacher's sense of stress, which may activate their biases or decrease their ability to manage classroom behaviors effectively.

Teacher perception plays a significant role in a child's suspension or expulsion risk. For example, the Preschool Expulsion Risk Measure addresses student behavior and teacher factors that can play a part in the adult decision of expulsion or suspension, such as the teacher's fear that the student's behavior would affect their job, a teacher's concern that the student's behavior would never be corrected, and teacher's feelings of stress related to the child's behavior (Gilliam \& Reyes, 2018). Authors of the measure contend that a child is not the person who decides on expulsion, it's an adult decision to remove a child from preschool (Gilliam $\&$ Reyes, 2018). While expulsion is referred to as an adult decision and there is significant speculation on what may influence this decision, there seems to be a lack in research about what specifically causes this decision to be made. One of the speculations could be that the teacher's perception of behavior plays a role in a child's risk for expulsion through the teacher-student relationship.

\section{Child Self-regulation \& Student-Teacher Relationships}

Preschool self-regulation has been linked to student-teacher relationships in a number of studies (Cadima et al., 2016; Loomis, 2021; McKinnon et al., 2018). Students with high levels of executive functioning skills have been correlated with high levels of closeness in the teacher-student relationship and low levels of executive functioning skills were correlated inversely, relating to low levels of closeness and high levels of conflict in the teacher-student relationships (McKinnon et al., 2018). This illustrates how children who have developed and learned executive functioning skills, such as those associated with self-regulation (i.e., problem solving, coping skills, impulse control, emotional regulation) seem to have closer relationships with their teachers.

There is ample evidence that student behaviors predict expulsion risk but not necessarily how this occurs. For example, there is variation in how teachers perceive and respond to challenging behavior, which may influence a teacher's 
decision making about moving toward expulsion or toward another strategy (Martin et al., 2018). One pathway that may influence this decision making is the student-teacher relationship. Student-teacher relationships are complex and can include dimensions of both closeness and conflict simultaneously (Silver et al., 2005). Student-teacher closeness may be uniquely protective for children who have poor selfregulation (Cadima et al., 2016; McKinnon et al., 2018). A teacher who feels warmly toward a child even in spite of their inability to self-regulate behavior may be less likely to request expulsion and more likely to try to engage in other school-based strategies, such as mental health consultation.

There is a wealth of information about disruptive behavior and the negative consequences and possible causes of conflictual teacher student relationships. Sabol and Pianta (2012) report that students with disruptive behavior are at risk for higher conflict relationships with teachers. The authors suggest that disruptive behavior and conflictual relationships create a cycle of negative interactions that perpetuates the conflict within the teacher-student relationship (Sabol \& Pianta, 2012). Students who have challenging behaviors may feel that they are constantly receiving corrections, and that correction could feel like a reflection of how their teacher perceives them. Conversely, teachers who are experiencing and constantly correcting negative behavior in the classroom may find it hard to perceive a child in a positive way or to build a close relationship with that student, thus further perpetuating the cycle of negative interaction within the teacher-student relationship.

Research has found that disruptive and aggressive behavior at the beginning of the year is predictive of conflictual teacher-student relationships (Sabol \& Pianta, 2012). This means that teachers are less likely to develop close relationships with students who display behaviors such as pushing, throwing, hitting, or other aggressive behaviors. This could be due to the stress the teachers feel from managing disruptive behaviors. It could also include negative teachers' perceptions that the student is unable to manage their behavior due to poor self-regulation skills. Sabol and Pianta (2012) also found that the aggressive behaviors were likely to increase by the end of the year, meaning the disruptive behavior of students only got worse as the year went on. This could indicate that the lack of closeness in the relationship could be a missing foundation that is necessary to develop self-regulation skills in young children.

All of this research could indicate that students with high levels of executive functioning skills, specifically higher ability to regulate their emotions, control their impulses and have less disruptive behaviors, teachers may feel less distress with those students and are able to develop closer relationships with those students, fostering a positive relationship to teach and build academic and social emotional skills for those children in preschool.

\section{Self-regulation, Student-Teacher Relationships, and Expulsion Risk}

Despite a plethora of evidence linking child behavior to expulsion risk, no research to date has examined the extent to which the teacher-child relationship may mediate (or buffer) the relationship between child behavior and expulsion risk. This is particularly important given the role of the student-teacher relationship in promoting school readiness (Blair \& Raver, 2015) and the stability of student-teacher relationships over time (Jerome et al., 2009). If student-teacher closeness is related to lower expulsion risk, and student-teacher closeness tends to be pretty stable from early childhood to later grades, then students who are at lower risk of expulsion early in schooling are likely to be at lower risk for expulsion later on as well. This would illustrate the reverse of the school-to-prison pipeline, in which the buffering effects of student-teacher relationships carry forward throughout a child's schooling.

A focus on the student-teacher relationship may also provide more clarity about how racial disparities in expulsion rates manifest. For example, even when adjusting for the influence of children's behavior, teachers report more student-teacher conflict for young Black children compared to their non-Black peers (Jerome et al., 2009; Loomis, 2021). It is likely that teacher biases influence not only how they perceive a child's behaviors but also how they interpret their relationship with that child and that both of these factors play a role in a child's expulsion risk.

\section{Current Study}

The current study helps to strengthen our understanding of the link between child behavior and expulsion risk in preschool by examining the mediating role of the student-teacher relationship in a sample of 88 children from 22 preschool classrooms. Our first aim is to confirm the relationship between child inhibitory control and expulsion risk, we anticipate finding that students with higher inhibitory control skills are at lower risk of expulsion. Our second aim is to determine whether student-teacher relationships mediates the relationship between child inhibitory control and expulsion risk. We anticipate finding that student-teacher closeness mediates the relationship between inhibitory control and expulsion prevention where higher control is related to more student-teacher closeness which is related to lower expulsion risk.

\section{Methods}

\section{Participants}

The current data is from the first wave of a pilot RCT of trauma-informed training among preschool staff, the 
baseline wave of data was collected prior to beginning the trauma-informed training. Lead (62\%) and assistant (38\%) preschool teachers were recruited from two Head Start programs in a Mountain West state in the fall of the 2020-2021 school year. Staff were informed about the study by a flyer that was emailed by program administrators that contained a link to the study survey. Teachers were eligible for the study if they were over the age of 18 , could participate in English, and had worked in their current program for more than 1 month, to allow for adequate time to form impressions of a child in their program or classroom. Of note, as this study took place during the COVID-19 pandemic, teachers were eligible to participate whether they were teaching in the classroom or virtually. Of the 22 teachers who took part in the baseline data collection, 17 (74\%) provided information about their teaching structure. Of those 17, 14 (61\%) taught primarily in person, $2(8.7 \%)$ taught primarily online, and 1 $(4.3 \%)$ taught an equal mix of in person and online. Teachers all identified as female, and were predominantly non-Latine White $(73 \%)$, followed by Latina (13.6\%), and American Indian $(4.5 \%)$. The average class size for participating teachers was 15 students (range 12-22).

\section{Procedures}

All teachers in both programs were recruited to take part in a study of trauma-informed training. Staff were emailed a flyer with study information and provided information during informational meetings. Consent was obtained and the survey was administered through Qualtrics survey software. Teachers were guided to randomly select four students from their class using a numbered class list and a random number generator. Teachers completed a short (15-min) survey on their own attitudes and characteristics and a short (5-10 min.) survey for each child related to behavior, relationship, and expulsion risk. The survey took approximately 45 min to complete and was available to complete over the computer or by smartphone. The survey was confidential and was available to take in English. Teachers were offered a \$40 gift card incentive for taking part in the survey. All study procedures were approved by the University of Utah Institutional Review Board.

\section{Measures}

\section{Child Behavior}

Child behavior was measured using the six-question inhibitory control subscale of the Child Behavior QuestionnaireTeacher Short Form (CBQ-TSF), a version of the Child Behavior Questionnaire adapted for use by preschool and kindergarten teachers (Teglasi et al., 2015). The CBQTSF asks teachers to rate the child on a 7-point Likert scale ranging from 1 (extremely untrue of your child) to 7 (extremely true of your child) on statements such as "can easily stop an activity when s/he is told "no"" $(\alpha=.77)$.

\section{Student-Teacher Closeness}

The student-teacher relationship was measured with the 7 -item closeness subscale $(\alpha=.81)$ of the Student-Teacher Relationship Scale-Short Form, a 15-question self-report measure of teachers' perceptions of their closeness and conflict with children from preschool through third grade (STRS-SF; Pianta, 2001). The closeness subscale asks teachers to rate statements such as "If upset this child will seek comfort from me" and "I share an affectionate, warm relationship with this child" using a 5-point Likert scale (ranging from "definitely does not apply" to "definitely applies"). The STRS-SF and full-form STRS have established reliability and validity with children and teachers from diverse ethnic and economic backgrounds (Cadima et al., 2016).

\section{Expulsion Risk}

Children's expulsion risk was measured using the Preschool Expulsion Risk Measure (PERM), a relatively new, twelveitem measure that has been found to predict the probability of a child being considered for expulsion (Gilliam \& Reyes, 2018). The measure has four subscales, including both childlevel factors and teacher-level factors as they relate to the student's risk of expulsion: classroom disruption, hopelessness, fear of accountability, and teacher stress. In the PERM, teachers are asked to rate statements such as "this child's classroom behaviors interfere with my ability to maintain control of the class" on a five-point Likert scale from one (strongly disagree) to five (strongly agree). The entire PERM score $(\alpha=.96)$, indicating total expulsion risk, was used for the current study.

\section{Covariates}

Covariates included child race/ethnicity, gender and class format (in person/virtual).

\section{Analysis}

Bivariate analyses, including chi-square tests for independence and t-test analyses were run to determine whether there were differences in key variables based on child demographic variables. A multiple regression was run to look at the relationship between student-teacher closeness and child inhibitory control and reports of child expulsion risk. Then an indirect effects path model was run to look at pathways from inhibitory control to expulsion risk through student-teacher closeness, where inhibitory control and 


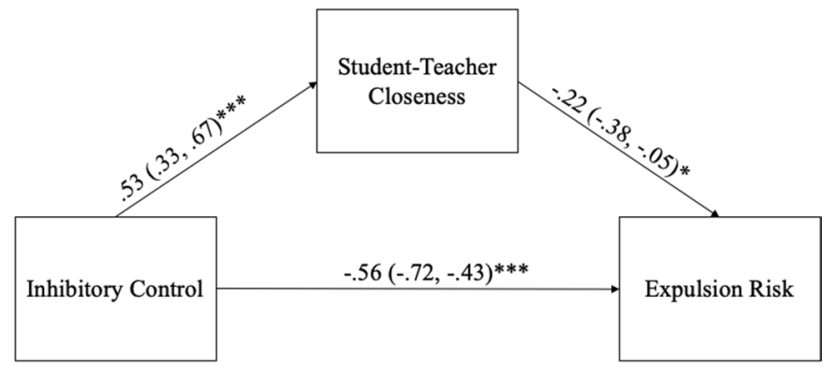

${ }^{*} \mathrm{p}<.05,{ }^{* * *} \mathrm{p}<.001$

Fig. 1 Indirect effects path model from inhibitory control to expulsion risk

Table 1 Key study variables $(N=92)$

\begin{tabular}{ll}
\hline & M (SD) \\
\hline CBQ inhibitory control & $5.04(1.31)$ \\
STRS closeness & $4.17(.73)$ \\
PERM & $1.83(1.07)$ \\
\hline Child demographics & $\mathrm{N}(\%)$ \\
\hline Child female & $40(43.5)$ \\
Child race/ethnicity & $9(9.8)$ \\
Latine/Hispanic & $50(54.3)$ \\
White & $17(18.5)$ \\
American Indian & $5(5.4)$ \\
Hawaiian/Pacific Islander & $3(3.3)$ \\
Asian & $1(1.1)$ \\
Black & $5(5.4)$ \\
Other* &
\end{tabular}

All child demographics are teacher-reported

*Other: not sure, prefer not to respond, race/ethnicity not reported

student-teacher closeness were mean centered. Dummy variables were created to represent student gender (female), and student ethnicity/race where separate variables were created to represent American Indian and Latine. Students of other racial and ethnic backgrounds were considered part of the reference group. A dummy variable was also included to represent class format as primarily virtual (with primarily in-person as the reference group).

Similar to other studies of student-teacher conflict and closeness (Loomis, 2021; McKinnon \& Blair, 2018), teacher ratings of closeness in this study were skewed, where teachers reported generally high levels of closeness with students. To account for this, the MLR estimator, which is robust to non-normal data, as well as bootstrapping (with 5000 iterations) was used. The MPlus "TYPE = COMPLEX" and "CLUSTER" option was used to correct standard errors for nesting within classrooms (Muthén \& Muthén, 1998). Standardized coefficients $(\beta)$ and bootstrapped confidence intervals are reported in Fig. 1. The following commonly accepted cut-offs of model fit were applied: Comparative Fit Index (CFI) of $\geq .90$, Tucker-Lewis Index (TLI) of $\geq .90$, Root Mean Square Error of Approximation (RMSEA) of $<.05$ and non-significant, and Standardized Root Mean Square Residual (SRMR) of $<.05$. Data cleaning as well as univariate and bivariate analyses were completed using SPSS for descriptive statistics and path models were estimated using Mplus.

\section{Results}

\section{Descriptive Statistics}

See Table 1 for descriptives of key study variables. Although within the normal range, expulsion risk was positively skewed (1.26), with a relatively low mean expulsion risk $(M=1.83)$ relative to a range of scores from 1 to 4.75 . This indicates teachers reported relatively low levels of expulsion risk for students. In contrast, average student-teacher closeness was high $(M=4.17$, skew $=-1.10)$ relative to the range of reported scores (1.86-5.0). The negative skew of student-teacher closeness scores also corresponds with other work on student-teacher relationships in which reported closeness tends to be high on average (Becker et al., 2017). 
Over half $(54.3 \%)$ of children randomly selected by teachers were White, about one in five $(18.5 \%)$ were American Indian, 10\% were Latine/Hispanic and almost half (43.5\%) were female).

Higher inhibitory control was correlated with higher student-teacher closeness $(r=.53, p<.001)$. Higher expulsion risk was significantly related to lower inhibitory control $(r=-.72, p<.001)$ and lower student-teacher closeness $(r=-.53, p<.001)$ and expulsion risk. Girls were rated as having higher inhibitory control than boys $\left(\mathrm{M}_{\mathrm{diff}}=.61\right.$, $\mathrm{t}=-2.19, p=.031)$ and marginally higher student-teacher closeness $\left(\mathrm{M}_{\text {diff }}=.28, \mathrm{t}=-1.86, p=.065\right)$ and lower expulsion risk $\left(\mathrm{M}_{\text {diff }}=-.45, \mathrm{t}=1.95, p=.053\right)$. There were no significant differences in student-teacher closeness or child inhibitory control based on class format, although children who were in primarily in-person classes had significantly higher expulsion risk $\left(\mathrm{M}_{\text {diff }}=.79, \mathrm{t}=-3.34, p=.002\right)$. There were no significant differences in key variables based on child race/ethnicity.

\section{Indirect Effects Model}

The results of the path analysis are presented in Fig. 1. The direct pathway from inhibitory control to expulsion risk was significant $(p<.001)$. The direct pathway from inhibitory control to student-teacher closeness was also significant $(p<.001)$ as was the pathway from student-teacher closeness to expulsion risk $(p=.007)$. The indirect effects, measuring the pathway from inhibitory control to expulsion risk through student-teacher closeness was also significant $(\beta=-.12, \mathrm{SE}=.05, p=.014)$, indicating that in addition to a significant direct effect of inhibitory control on expulsion risk, inhibitory control also had an influence on expulsion risk through student-teacher closeness. Child demographics (gender, ethnicity, race) were not significantly related to expulsion risk in the model. Although class format was not significant $(\beta=-.21, p=.076)$, it did trend in a direction suggesting lower expulsion risk for students who were in a primarily virtual class. The variables in the model predicted $57 \%$ of the variance in expulsion risk $(p<.001)$.

\section{Discussion}

Overall, this study aimed to examine the relationship between child inhibitory control and expulsion risk, and to further determine whether student-teacher closeness mediated the relationship between child inhibitory control and expulsion risk among preschool students. While an abundance of evidence has linked child behaviors to school expulsion across a range of ages, student-teacher closeness has not been as widely examined in the context of expulsion prevention, particularly in preschool contexts. In the present study, as expected, more positive inhibitory control was related to lower expulsion risk as reported by teachers. This is particularly notable given the positive skew in ratings of inhibitory control among students in the study, suggesting that even small improvements in inhibitory control for students with already sufficient skills may be related to reductions in expulsion risk.

Inhibitory control is a piece of self-regulation, or children's ability to modulate their thoughts, feelings, and emotions. A number of child-focused interventions have been found to improve children's self-regulation skills, particularly children with low baseline levels of self-regulation (Graziano \& Hart, 2016; Tominey \& McClelland, 2011). However, self-regulation is likely also part of a bi-directional construct related to safety in the school context, demonstrating the importance not just of improving children's selfregulation skills but also improving the school environment in which those skills can develop. Approaches that focus on teacher stress levels, classroom and school climate, and trauma-informed training for school staff may help to support safety within the school environment and support children's self-regulation skills as well as teachers' perceptions of children's ability to self-regulation.

Children with positive inhibitory skills likely follow directions easier and have less difficulty transitioning away from activities. As a result, these children may be perceived by teachers as more compliant and agreeable, which may lead to more positive and warm interactions between the teacher and child, which may decrease the likelihood that a teacher would move toward expulsion for that child. Indeed, the pathway from student-teacher closeness to expulsion significant and negative, suggesting that more student-teacher closeness was related to lower expulsion risk. The indirect pathway from inhibitory control to expulsion risk through student-teacher closeness was also significant, indicating that student-teacher closeness is one mechanism through which stronger behavioral inhibition reduces expulsion risk. These findings are notable in the context of the COVID pandemic, in which many parents reported increases in tantrums, anxiety and clinginess (Egan et al., 2021) and early childhood educators reported declining physical and mental health (Swigonski et al., 2021).

Of note, in the current study the direct pathway from inhibitory control to expulsion risk was still significant, suggesting that there are other factors aside from student-teacher closeness that may play a role in children's expulsion risk. Prior work had examined the role of student-teacher closeness in the presence of conflict, for example students who have warm moments with teachers even in spite of also having high conflict moments with teachers. This may be highly relevant in the context of expulsion prevention. 
Additionally, in the current study the association between class format (e.g., primarily in person or virtual) and expulsion risk trended in a significant direction in which children in virtual classrooms were at lower risk of expulsion. This is an area of future consideration as schools continue to struggle with the need for virtual learning in the face of the ongoing pandemic as well as increased use of virtual schooling within early care and education contexts overall. It is unclear whether young children who are in school virtually are not demonstrating the same challenging behaviors as students who are in the classroom because of some of the positives of virtual education (e.g., more time to play with siblings) (Egan et al., 2021) or simply are subject to less monitoring from teachers, who may then be less likely to pick up on children's behaviors.

\section{Implications for Practice and Policy}

Despite relatively widespread understanding of the high rates of preschool expulsion seen nationally, and risks associated with school discipline, the evidence for practices and policies that can reduce these rates and associated risks is lacking. A recent review of the existing state-wide legislation related to reducing preschool expulsion identified a need for more evidence-based interventions that can reduce rates and disparities within the rates of preschool expulsion (Loomis et al., 2021). The current study provides support for the role of interventions that aim to improve student-teacher relationships as central in expulsion prevention efforts, particularly interventions that focus on changing teacher perceptions (in tandem with or in lieu of an explicit focus on child behaviors). Teachers who perceive their relationships with children as more positive may feel less overwhelmed by a child's specific challenging behaviors or may be more likely to engage in supportive responses (e.g., scaffolding emotion regulation) than moving toward punitive responses such as expulsion. There are existing interventions that have been found to effectively increase student-teacher closeness in preschool settings that warrant future exploration in the context of expulsion prevention. For example, Banking Time is an approach in which teachers have one-on-one regular meetings with a child in which they observe and narrate the child's actions, label the child's feelings/emotions, and develop relational themes. A randomized control study of the intervention found that Banking Time was associated with more teacher-reported student-teacher closeness (Driscoll \& Pianta, 2010). Banking Time has even been associated with declines in cortisol among a sample of preschool children (Hatfield \& Williford, 2017). Early childhood mental health consultation is another approach that focuses in part on supporting teachers in addressing children's challenging behaviors by reflecting on their responses to the child's behavior and has been positioned as a promising approach to preventing preschool expulsion (Carlson et al., 2012; Children's Equity Project \& the Bipartisan Policy Center, 2020; Davis et al., 2020; Perry et al., 2008). It is also important to address teacher stress levels and work conditions that may contribute to higher risk of harsh discipline (Zinsser et al., 2017) and poor student-teacher relationships (Gagnon et al., 2019). In tandem with policy recommendations to prohibit or restrict the use of exclusionary discipline, particularly among preschoolers, it is important that such policies are paired with funding for such prevention, promotion and interventions (Children's Equity Project \& the Bipartisan Policy Center, 2020).

Although the current study did not find a relationship between child demographics (e.g., race/ethnicity and gender) this should be taken as a reflection of the study sample rather than the context of expulsion risk. Students of color, particularly Black boys, are suspended and expelled at disproportionate rates compared to their peers (Rumberger \& Losen, 2016; U.S. Department of Education Office for Civil Rights, 2014). This is in part driven by teacher implicit and explicit biases; for example, teachers are more likely to look for problematic or challenging behavior in Black boys than other students (Gilliam et al., 2016). Jerome et al. (2009) also found racial differences in early childhood teacher-student relationships, in which teachers were more likely to report higher levels of conflict with Black students than their white counterparts, a pattern that continued as children moved from grades K-6. Among older students, improving the empathetic mindsets of teachers can improve student perceptions of the student-teacher relationship and decrease discipline rates (Okonofua et al., 2016), which may be incorporated into ECE settings to address the role of bias in early childhood educators' perceptions of student-teacher relationships. Although the current study does not add to this body of work, we affirm the need to adapt existing equityoriented interventions for the ECE setting and to ensure that any practices aimed at improving student-teacher relationships are grounded in a culturally responsive framework in order to address the role of teacher biases and the ways in which culture may inform student-teacher relationships in early childhood settings (Children's Equity Project \& the Bipartisan Policy Center, 2020).

\section{Limitations and Future Research}

This paper solidifies the importance of student-teacher closeness in preventing expulsion risk for students. However, despite the notable importance of these findings, they should be interpreted with caution based on the following limitations. First, the small sample of teachers and students limits the power of our findings as well as our ability to conduct more 
complex hierarchical analyses that are often used with nested data. The small sample also made it difficult to examine the research questions among subgroups of students, for example students for which there was a racial/ethnic match with their teacher. Racial/ethnic congruence between teachers and students has been found to influence student-teacher relationships (Yiu, 2013) and discipline risk (Blake et al., 2016) and should be examined within the context of expulsion risk in a larger, more diverse sample of preschoolers. Our sample was also limited in terms of racial/ethnic diversity; notably over half of students being identified as White and only $1 \%$ as Black. Black children are at significantly higher risk of expulsion compared to White children (Children's Equity Project \& the Bipartisan Policy Center, 2020), disparities that are likely linked to ways in which teacher racial biases influence how they perceive student behavior and student-teacher relationships differently, which we were not able to examine in the current study.

Additionally, data collection for this study took place during the COVID-19 pandemic, which likely influenced relationship building with students over virtual platforms, child socio-emotional health, and stress levels of staff (Eadie et al., 2021; Egan et al., 2021; Patrick et al., 2020). Although we took teaching format (virtual/in person) into consideration in our analyses, the use of a simple dummy variable did not take into consideration the other nuances that likely played into teacher's perceptions of their relationships with students and children's expulsion risk. As the current study is part of a larger study of a trauma-informed training among preschool teachers, it is also possible that teachers who elected to participate in the training (who make up the baseline wave of data that is used here) differed from teachers who opted out of the training in some significant ways.

Further, the use of actual expulsion data, rather than expulsion risk, would have strengthened our ability to make determinations about the tangible outcomes associated with student-teacher closeness. Future research should consider whether interventions that aim to promote student-teacher closeness is associated with actual reductions in expulsion risk. Longitudinal data that allows for cross-lagged examination of the bidirectional relationship between perceived child behavior, expulsion risk, and student-teacher relationships would also add richness to our study findings.

Finally, the current study used data from the same informant on all three measures. In some ways this is highly relevant to the subjective nature of expulsion risk, because in a sense expulsion risk is driven in large part by teacher perceptions of student behavior and their perceptions of their relationships. However, future work should also integrate observational measures of student behavior and student-teacher relationships to identify the true contribution of teachers' perceptions of behaviors compared to observed behavior to expulsion and expulsion risk for young students.

\section{Conclusion}

In this study, direct pathways from children's inhibitory control and student-teacher closeness to child expulsion risk were significant as was the indirect pathway from inhibitory control to expulsion risk through student-teacher closeness. This study contributes to existing research on child expulsion risk by providing more support of the importance of the student-teacher relationship to buffering pathways to expulsion and highlighting the role of relationship-focused interventions within the preschool context.

\section{References}

Barnes, J. C., \& Motz, R. T. (2018). Reducing racial inequalities in adulthood arrest by reducing inequalities in school discipline: Evidence from the school-to-prison pipeline. Developmental Psychology, 54(12), 2328-2340.

Becker, B., Gallagher, K., \& Whitaker, R. (2017). Teachers' dispositional mindfulness and the quality of their relationships with children in Head Start classrooms. Journal of School Psychology, $65,40-53$.

Blair, C., \& Raver, C. C. (2015). School readiness and self-regulation: A developmental pyschobiological approach. Annual Review of Psychology, 66, 711-731. https://doi.org/10.1146/annurev-psych010814-015221.School

Blake, J. J., Smith, D. M., Marchbanks, M. P., III., Seibert, A. L., Wood, S. M., \& Kim, E. S. (2016). Does student-teacher racial/ ethnic match impact Black students' discipline risk? A test of the cultural synchrony hypothesis. In R. J. Skiba, K. Mediratta, \& M. K. Rausch (Eds.), Inequality in school discipline (pp. 79-98). Palgrave Macmillan.

Cadima, J., Verschueren, K., Leal, T., \& Guedes, C. (2016). Classroom interactions, dyadic teacher-child relationships, and selfregulation in socially disadvantaged young children. Journal of Abnormal Child Psychology, 44(1), 7-17. https://doi.org/10.1007/ s10802-015-0060-5

Carlson, J. S., Mackrain, M. A., van Egeren, L. A., Brophy-Herb, H., Kirk, R. H., Marciniak, D., Falvay, S., Zheng, Y., Bender, S. L., \& Tableman, B. (2012). Implementing a statewide early childhood mental health consultation approach to preventing childcare expulsion. Infant Mental Health Journal, 33(3), 265-273. https:// doi.org/10.1002/imhj.21336

Children's Equity Project \& the Bipartisan Policy Center. (2020). Start with equity: From the early years to the early grades data, research, and an actionable child equity policy agenda. Retrieved from https://childandfamilysuccess.asu.edu/sites/default/files/ 2020-10/CEP-report-101320-FINAL_0.Pdf

Davis, A. E., Perry, D. F., \& Rabinovitz, L. (2020). Expulsion prevention: Framework for the role of infant and early childhood mental health consultation in addressing implicit biases. Infant Mental Health Journal. https://doi.org/10.1002/imhj.21847

Driscoll, K. C., \& Pianta, R. C. (2010). Banking time in Head Start: Early efficacy of an intervention designed to promote supportive teacher-child relationships. Early Education \& Development, 21(1), 38-64. https://doi.org/10.1080/10409280802657449

Eadie, P., Levickis, P., Murray, L., Page, J., Elek, C., \& Church, A. (2021). Early childhood educators' wellbeing during the COVID19 pandemic. Early Childhood Education Journal. https://doi.org/ 10.1007/s10643-021-01203-3 
Egan, S. M., Pope, J., Moloney, M., Hoyne, C., \& Beatty, C. (2021). Missing early education and care during the pandemic: The socio-emotional impact of the COVID-19 crisis on young children. Early Childhood Education Journal. https://doi.org/10. 1007/s10643-021-01193-2

Gagnon, S. G., Huelsman, T. J., Kidder-Ashley, P., \& Lewis, A. (2019). Preschool student-teacher relationships and teaching stress. Early Childhood Education Journal, 47, 217-255.

Gilliam, W. S. (2005). Prekindergarteners left behind: Expulsion rates in state prekindergarten systems. In Yale University Child Study Center. http://fcd-us.org/sites/default/files/ExpulsionC ompleteReport.pdf

Gilliam, W. S., Maupin, A. N., Reyes, C. R., Accavitti, M., Shic, F., Fontaine, J. J., Holloway, C., \& Stevenson, H. (2016). Do early educators' implicit biases regarding sex and race relate to behavior expectations and recommendations of preschool expulsions and suspensions? https://medicine.yale.edu/child study/zigler/publications/Preschool\%20Implicit\%20Bias\%20Pol icy\%20Brief_final_9_26_276766_5379_v1.pdf

Gilliam, W. S., \& Reyes, C. R. (2018). Teacher decision factors that lead to preschool expulsion: Scale development and preliminary validation of the Preschool Expulsion Risk Measure. Infants \& Young Children, 31(2), 93-108. https://doi.org/10.1097/IYC. 0000000000000113

Gilliam, W. S., \& Shahar, G. (2006). Preschool and child care expulsion and suspension: Rates and predictors in one state. Infants \& Young Children, 16(3), 228-245. https://doi.org/10.1097/00001 163-200607000-00007

Giordano, K., Interra, V. L., Stillo, G. C., Mims, A. T., \& Block-Lerner, J. (2020). Associations between child and administrator race and suspension and expulsion rates in community childcare programs. Early Childhood Education Journal. https://doi.org/10.1007/ s10643-020-01049-1

Graziano, P. A., \& Hart, K. (2016). Beyond behavior modification: Benefits of social-emotional/self-regulation training for preschoolers with behavior problems. Journal of School Psychology, 58, 91-111. https://doi.org/10.1016/j.jsp.2016.07.004

Hatfield, B. E., \& Williford, A. P. (2017). Cortisol patterns for young children displaying disruptive behavior: Links to a teacher-child, relationship-focused intervention. Prevention Science, 18(1), 40-49. https://doi.org/10.1007/s11121-016-0693-9

Hooper, A., \& Schweiker, C. (2020). Prevalence and predictors of expulsion in home-based child care settings. Infant Mental Health Journal. https://doi.org/10.1002/imhj.21845

Hughes, T., Raines, T., \& Malone, C. (2020). School pathways to the juvenile justice system. Policy Insights from the Behavioral and Brain Sciences, 7(1), 72-79. https://doi.org/10.1177/2372732219 897093

Iruka, I. U., Lewis, M. L., Lozada, F. T., Bocknek, E. L., \& BrophyHerb, H. E. (2021). Call to action: Centering Blackness and disrupting systemic racism in infant mental health research and academic publishing. Infant Mental Health Journal, 42(6), 745-748.

Jerome, E. M., Hamre, B. K., \& Pianta, R. C. (2009). Teacher-child relationships from kindergarten to sixth grade: Early childhood predictors of teacher-perceived conflict and closeness. Social Development, 18(4), 915-945. https://doi.org/10.1111/j.14679507.2008.00508.x

Kahle, S., Utendale, W. T., Widaman, K. F., \& Hastings, P. D. (2018). Parasympathetic regulation and inhibitory control predict the development of externalizing problems in early childhood. Journal of Abnormal Child Psychology, 46(2), 237-249. https://doi. org/10.1007/s10802-017-0305-6

Loomis, A. M. (2021). The influence of early adversity on self-regulation and student-teacher relationships in preschool. Early Childhood Research Quarterly, 54, 294-306. https://doi.org/10.1016/j. ecresq.2020.10.004
Loomis, A. M., Davis, A., Cruden, G., Padilla, C., \& Drazen, Y. (2021). Early childhood suspension and expulsion: A content analysis of state legislation. Early Childhood Education Journal. https://doi. org/10.1007/s10643-021-01159-4

Malik, R. (2017). New data reveal 250 preschoolers are suspended or expelled every day. Retrieved from https://www.americanpr ogress.org/issues/earlychildhood/news/2017/11/06/442280/newda ta-reveal-250-preschoolers-suspended-expelledeveryday/

Martin, K. A., Bosk, E., \& Bailey, D. (2018). Teachers' perceptions of childcare and preschool expulsion. Children and Society, 32(2), 87-97. https://doi.org/10.1111/chso.12228

McKinnon, R. D., \& Blair, C. (2018). Bidirectional relations among executive function, teacher-child relationships, and early reading and math achievement: A cross-lagged panel analysis. Early Childhood Research Quarterly, 46, 152-165. https://doi.org/10. 1016/j.ecresq.2018.03.011

McKinnon, R. D., Blair, C., Vernon-Feagans, L., Greenberg, M., Cox, M., Blair, C., Burchinal, P., Willoughby, M., Garrett-Peters, P., Mills-Koonce, R., \& Ittig, M. (2018). Does early executive function predict teacher-child relationships from kindergarten to second grade? Developmental Psychology, 54(11), 2053-2066. https://doi.org/10.1037/dev0000584

Melzi, G., McWayne, C., \& Ochoa, W. (2020). Family engagement and Latine children's early narrative skills. Early Childhood Education Journal. https://doi.org/10.1007/s10643-020-01132-7

Miller, S., Smith-Bonahue, T., \& Kemple, K. (2017). Preschool teachers' responses to challenging behavior: The role of organizational climate in referrals and expulsions. International Research in Early Childhood Education, 8(1), 38-57.

Muthén, L., \& Muthén, B. (1998). Mplus user's guide (7th ed.). https:// doi.org/10.1111/j.1600-0447.2011.01711.x

Noltemeyer, A. L., Ward, R. M., \& Mcloughlin, C. (2015). Relationship between school suspension and student outcomes: A metaanalysis. School Psychology Review, 44(2), 224-240. https://doi. org/10.17105/spr-14-0008.1

Okonofua, J. A., Paunesku, D., \& Walton, G. M. (2016). Brief intervention to encourage empathic discipline cuts suspension rates in half among adolescents. Proceedings of the National Academy of Sciences of the United States of America, 113(19), 5221-5226. https://doi.org/10.1073/pnas.1523698113

Patrick, S. W., Henkhaus, L. E., Zickafoose, J. S., Lovell, K., Halvorson, A., Loch, S., Letterie, M., \& Davis, M. M. (2020). Wellbeing of parents and children during the COVID-19 pandemic: A national survey. Pediatrics, 146(4), e2020016824. https://doi.org/ 10.1542/peds.2020-016824

Perry, D. F., Dunne, M. C., McFadden, L. T., \& Campbell, D. (2008). Reducing the risk for preschool expulsion: Mental health consultation for young children with challenging behaviors. Journal of Child and Family Studies, 17(1), 44-54. https://doi.org/10.1007/ s10826-007-9140-7

Pianta, R. C. (2001). Student-teacher relationship scale (STRS): Professional manual. Psychological Assessment Resources, Inc.

Rumberger, R. W., \& Losen, D. J. (2016). The high cost of harsh discipline and its disparate impact. Retrieved from the Center for Civil Rights Remedies at the Civil Rights Project website: https://civil rightsproject.ucla.edu/resources/projects/center-for-civil-rightsremedies/school-to- prison-folder/federal-reports/the-high-costof-harsh-discipline-and-its-disparate-impact

Sabol, T. J., \& Pianta, R. C. (2012). Recent trends in research on teacher-child relationships. Attachment \& Human Development, 14(3), 213-231. https://doi.org/10.1080/14616734.2012.672262

Silver, R. B., Measelle, J. R., Armstrong, J. M., \& Essex, M. J. (2005). Trajectories of classroom externalizing behavior: Contributions of child characteristics, family characteristics, and the teacherchild relationship during the school transition. Journal of School Psychology, 43(1), 39-60. 
Skowron, E. A., Cipriano-Essel, E., Gatzke-Kopp, L. M., Teti, D. M., \& Ammerman, R. T. (2014). Early adversity, RSA, and inhibitory control: Evidence of children's neurobiological sensitivity to social context. Developmental Psychobiology, 56(5), 964-978. https://doi.org/10.1002/dev.21175

SNAHEC. (2019). From boarding schools to suspension boards: Suspensions and expulsions of Native American students in California public schools. https://cceal.org/wp-content/uploads/2019/09/ Suspension-Boards-Final.pdf

Swigonski, N. L., James, B., Wynns, W., \& Casavan, K. (2021). Physical, mental, and financial stress impacts of COVID-19 on early childhood educators. Early Childhood Education Journal. https:// doi.org/10.1007/s10643-021-01223-z

Teglasi, H., Schussler, L., Gifford, K., Annotti, L. A., Sanders, C., \& Liu, H. (2015). Child Behavior Questionnaire-Short Form for teachers. Assessment, 22(6), 730-748. https://doi.org/10.1177/ 1073191114562828

Tominey, S. L., \& McClelland, M. M. (2011). Red light, purple light: Findings from a randomized trial using circle time games to improve behavioral self-regulation in preschool. Early Education and Development, 22(3), 489-519. https://doi.org/10.1080/10409 289.2011.574258

U.S. Department of Education Office for Civil Rights. (2014). Data snapshot: Early childhood education (suspension policies in early childhood settings). U.S. Department of Education Office for Civil Rights.
Yiu, H. L. (2013). The influence of student-teacher racial match on student-teacher closeness: A focus on Asian and Asian American students. Asian American Journal of Psychology, 4(2), 126-135. https://doi.org/10.1037/a0027785

Zeng, S., Corr, C. P., Grady, C. O., \& Guan, Y. (2019). Adverse childhood experiences and preschool suspension expulsion: A population study. Child Abuse \& Neglect. https://doi.org/10.1016/j. chiabu.2019.104149

Zinsser, K. M., Zulauf, C. A., Nair Das, V., \& Callie Silver, H. (2017). Utilizing social-emotional learning supports to address teacher stress and preschool expulsion. Journal of Applied Developmental Psychology. https://doi.org/10.1016/j.appdev.2017.11.006

Zulauf, C. A., \& Zinsser, K. M. (2019). Forestalling preschool expulsion: A mixed-method exploration of the potential protective role of teachers' perceptions of parents. American Educational Research Journal, 56(6), 2189-2220. https://doi.org/10.3102/ 0002831219838236

Publisher's Note Springer Nature remains neutral with regard to jurisdictional claims in published maps and institutional affiliations. 